\title{
An Empirical Study of the Impact of Review Extremity on Negative Online Review Helpfulness
}

Zheng Huihui ${ }^{*}$, Zhou Xiaoman

School of Management, Jinan University, Guangzhou,China

DOI: $10.36347 /$ sjebm.2020.v07i01.001

| Received: 21.12.2019 | Accepted: 09.01.2020 | Published: 16.01.2020

*Corresponding author: Zheng Huihui

Abstract

Original Research Article

Previous studies did not discuss extremely positive and extremely negative reviews separately, which leads to inconsistent conclusions regarding the role of review extremity in predicting review helpfulness. Meanwhile, the direct relationship between review extremity and review helpfulness has been extensively explored in literature, but few studies on the moderating effect are available to reveal the boundary conditions of this effect. Therefore, this study focuses on the impact of extremity of negative reviews on the helpfulness of reviews and further explores the moderating role of review characteristics and product type. 86,930 negative reviews of hotels from Ctrip.com were used to perform Negative binomial regression to test our research model. Our findings reveal that for negative reviews, review extremity has a significant positive impact on review helpfulness, and the impact is much stronger when negative reviews are associated with lower hotel star level, photos and longer length. This study enriches the theoretical research of online review helpfulness and provides some managerial suggestions for online platforms and enterprise managers.

Keywords: Review extremity; negative review helpfulness; hotel star level; review photo; review length.

Copyright @ 2020: This is an open-access article distributed under the terms of the Creative Commons Attribution license which permits unrestricted use, distribution, and reproduction in any medium for non-commercial use (NonCommercial, or CC-BY-NC) provided the original author and source are credited.

\section{INTRODUCTION}

With the rapid development of information technology and e-commerce, online shopping has become a mainstream shopping way. According to data from China Internet Network Information Center (CNNIC), as of June 2018, the number of online shopping users in China had reached 569 million, up $6.7 \%$ from the end of 2017 , accounting for $71.0 \%$ of the total number of Internet users. Compared with the traditional offline shopping, online shopping can overcome temporal and spatial constraints, with the advantages of convenience, rapidity and low cost. However, consumers cannot truly feel the quality of products or services before purchase, thus increasing the purchase risk [1]. In order to minimize the possible loss caused by the purchase decision, online reviews become an important information source for consumers to learn about the quality of products or services [2]. Nearly half of the tourists browse online reviews of hotels before confirming their accommodation [3]. $65 \%$ of tourists search for information online before choosing a destination, and $69 \%$ of them decide on a destination based on online travel reviews [4].

Online reviews can be defined as peergenerated product evaluations posted on company or third party web sites [5], which can influence consumers' purchase intention [6] and sales of products or services [7, 8]. But not all consumers are willing to post reviews. Consumers who are extremely satisfied or dissatisfied tend to be more motivated to comment, which leads to extreme reviews (extremely positive and negative) appearing more frequently and commonly in the review system [9]. However, research in eWOM has found mixed results about the effect of extreme reviews on review helpfulness. For instance, Park et al., [10] found that reviews with extreme ratings (both negative and positive) are voted as helpful by consumers and similar findings were obtained by other scholars [11, 12]. Nevertheless, Yin et al., [13] reveal that extreme reviews tend to be perceived as subjective and thus unhelpful for consumer decision making, so there is a negative correlation between review extremity and review helpfulness. Some scholars have pointed out that the reason for these mixed findings may be due to the fact that existing studies did not measure separately the effect of extremely negative and extremely positive reviews on the helpfulness of the review, but extremely negative and extremely positive reviews are different in terms of the motivations for posting them and their usage in consumer decision making [14]. In view of this, we take negative online reviews as the starting 
point and focus on the impact of review extremity on the helpfulness of reviews. Meanwhile, previous studies explored the direct influence of review extremity on review helpfulness, but the factors moderating the relationship between them have not been investigated. Therefore, this article further explores the regulatory role of review characteristics and product type.

Most studies recognize the importance of message characteristics in the analysis of factors influencing a consumer's decision to vote a review as helpful $[15,16]$, but there is no research to explore how the extremity of negative reviews affects review helpfulness in different dimensions of review features [14]. In addition, some scholars pointed out that product type is an important factor that regulates the relationship between review extremity and review helpfulness. For instance, Jiang [11] found that compared with search products, review extremity has a stronger positive impact on the review helpfulness of experience product. So, this paper uses Ctrip's 89,530 hotel negative reviews as the basic data to explore the impact of review extremity on review helpfulness, and selects two important review features (review length and review photo) as moderators. Moreover, as the research object of this article is hotel online reviews, hotel star level, as an important classification criterion for hotel type, may be a potential moderator [14], thus also included in the research framework.

\section{LITERATURE REVIEW Online Review Helpfulness}

Review helpfulness can be seen as a reflection of review diagnosticity [5], that is, how helpful the review is for consumers to make final purchasing decisions, emphasizing consumers' subjective feelings. In order to help consumers better identify highly useful reviews, many e-commerce websites set up review helpfulness voting mechanism in its review system, encouraging the users to evaluate the helpfulness of reviews written by other users. This is traditionally done by asking review readers "Is this review useful to you?" and the usefulness of reviews is generally assessed by the number of votes they received.

The determinants of review helpfulness have been widely studied. Based on an extensive literature search, we found the explored factors so far are: the review characteristics, including rating scores [15, 10], review length [5, 13], review readability [17], review timeliness [18], subjectivity and objectivity of review [19] and review photo [20, 17]; the reviewer characteristics, including personal information disclosure [21], the number of reviewer's historical comments [22, 16], reviewer rank [22], and reviewer centrality [16]; the review reader characteristics, including involvement [23], previous attitudes towards product [24-26], product consumption goals [27], professional level [28] and the similarity between review readers and reviewers [29]; the platform type, including seller platform (such as Taobao), third-party review platform (such as Dianping) and consumer selfbuilt platform (such as blog and microblog), and there is a certain difference between the helpfulness of online reviews on different platforms [30,31]. To sum up, although previous scholars have conducted extensive discussions on the factors influencing the helpfulness of online reviews, most of them focused on the factors directly affecting helpfulness but lack of discussion on the regulating factors.

\section{Online Negative Review}

Nathalia et al., [32] defined review valence as the positive and negative directions of the review, which can be positive, neutral, and negative [15]. In the current 5-point evaluation system, negative reviews are less than 3 points, neutral reviews are 3 points, and positive reviews are higher than 3 points. As one of the more intuitive features of online reviews, review valence has attracted the attention of many scholars. Some studies have found that negative reviews are more useful than positive ones, which is referred to as negativity bias in eWOM $[15,33]$. There are three main explanation mechanisms: (1) The explanation based on attribution theory believes that consumers will try to infer the reviewer's motivation through some clues when reading reviews [34], and consumers' perception of review helpfulness is largely determined by their different attributions to reviewer's motivation [35, 31]. If consumers attribute a review to external product factors (e.g., product experience), the review will be of high helpfulness, while if the review is considered to the reviewer's personal subjective reasons, consumers will perceive the review as less helpful [35]. Compared with negative reviews, positive online reviews are more attributed to the reviewers, so their value will decrease, leading to negativity bias. (2) The explanation based on evolution theory suggests that people are more likely to survive and thrive if they pay close attention to negative events [36], so negative reviews are more helpful. (3) According to the prospect theory, people are more sensitive to losses than gains. Negative reviews mean that there is a risk of loss after purchasing the product. Out of aversion and avoidance of losses, consumers tend to attach more importance to such negative reviews and consider them more informative. But not all negative reviews are useful. Most scholars have studied all the reviews as a whole, while this article focuses on negative reviews and investigates what kind of negative reviews (review extremity) have a greater impact on consumers' purchase intentions.

\section{Research Hypothesis}

\section{Extremely Negative Reviews and Review Helpfulness}

Among negative reviews, extreme negative ones are those that have received the lowest rating, which is shown as reviews with a score of 1 in a 5-point rating system [14]. The closer the score is to 1 , the more extreme the negative reviews are. Previous studies have 
pointed out that there is a positive relationship between review extremity and review helpfulness, that is, extreme reviews are perceived to be more useful than moderate reviews $[10,2,11,12]$. In other words, extreme reviews have higher information value and stronger impact on consumers, which is consistent with information diagnosis theory [37]. Information diagnostics refers to the degree to which information can help consumers make judgments or decisions. Specifically, when the information enables consumers to make clear judgments, it has better diagnostics, but when the content of the information is ambiguous, it is poorly diagnostic. Bone's [38] research indicated that whether a review has better diagnostics depends on how easy it is for consumers to make judgment and decision on the quality of a certain product, and the lower the difficulty, the higher the diagnostic value. In the case of eWOM environment, extreme reviews are highly diagnosable to help consumers judge the quality of a product, while moderate reviews contain ambiguous information and have low diagnostics [11]. Therefore, the more extreme the negative review score is, the more clearly the reviewer's strong dissatisfaction with the quality of the product or service is expressed, which is conducive to consumers' judgment on the quality of the product or service. Therefore, we hypothesize the following:

H1. Extremely negative reviews will have a positive impact on review helpfulness.

\section{The moderating effect of hotel star level}

Confirmation bias theory holds that when people initially establish a certain belief or opinion, they will pay more attention to information that is consistent with and supports the previous belief or opinion in the process of information search and adoption [39]. This phenomenon also exists in online reviews. Li and Zhan [24] found that review readers' previous attitudes towards the product would significantly affect the helpfulness of reviews, and those who previously hold a positive attitude towards the product are more likely to perceive positive reviews as useful. Yin et al., [25] reveal that the average rating of product reviews is the basis for customers to form their initial product attitude, and the larger the deviation between the score of product review and the average score of product reviews, the higher the deviation from their original product attitudes, so the lower the usefulness of the review. Mafael et al., [26] indicated that negative reviews are perceived to be more useful when individuals have a negative attitude towards a brand, in contrast, positive reviews are perceived to be more useful when individuals have a positive attitude towards the brand. In other words, when received information is consistent with and confirm the individual's previous beliefs, they will consider the information as more convincing, but when the received information is inconsistent with or violates previous beliefs, they will consider the information as more unconvincing [26].

Hotel star level is a representation of the quality of products or services provided by the hotel. The higher the star level, the higher the quality, which is a potential belief or viewpoint formed by consumers. A hotel that receives extremely negative reviews (one score rating) is more likely to be perceived as belonging to the category of low quality hotels. Therefore, the higher the hotel's star level, the greater the deviation between the low hotel quality (received information) represented by the extreme negative reviews and the quality (previous belief) represented by the hotel's star level, which violate the consumer's previous beliefs. So extremely negative review is not considered as convincing, and the helpfulness of it will be reduced. Thus, we hypothesize the following:

H2. Hotel star level can moderate the influence that extremely negative reviews have on review helpfulness. Compared with low-star hotel, the positive influence of extremely negative reviews on review helpfulness of high-star hotel is weaker.

\section{The Moderating Effect of Review Photos}

In the context of e-commerce, consumers can improve their cognition of a product or service by searching for multiple clues about the product or service [40]. Compared with review text, review photo (visual information) is considered as a vivid display of products or services [41]. Mitchell and Olson [42] argue that visual information has greater impact on changes in consumer's attitudes towards to brand or product than verbal or textual information. Previous studies have shown that in the context of online reviews, visualized pictures can affect review readers' acceptance of online reviews and their willingness to use them. Filieri [20] found that photos or video posted by customers about the product can enhance the vividness of reviews. In addition, compared with the pictures published by merchants, the pictures posted by reviewers are more credible, and more helpful for consumers to evaluate products objectively, then enhances consumer trust in the reviews and reviewers [43]. Yang et al., [17] divided the photo clues into food and drink pictures and restaurant environment pictures, and found that the more photos included in the review, the higher pleasure the review was perceived, thus having a higher helpfulness. Therefore, text information and photo information are used as two forms of displaying hotel products or services, their combination can improve consumers' perception and acceptance of online reviews. Following the principle of "seeing is believing", extremely negative reviews are more credible and more helpful if accompanied by photos. Thus, we hypothesize the following:

H3. Review photos can moderate the influence that extremely negative reviews have on review helpfulness. 
Compared with negative reviews without photos, the positive influence of extremely negative reviews on review helpfulness of negative reviews with photos is stronger.

\section{The Moderating Effect of Review Length}

Review length is also called review depth, and is usually indicated by the number of words in a review. Numerous studies have proved that the length of the review message has a positive impact on review helpfulness $[5,33,12,13]$. They think that long reviews may contain richer information and provide more comprehensive product information to consumers than short reviews [44]. Moreover, longer reviews tend to be considered as more time and effort invested and thus more credible [43]. Since hotels provide various services, consumers often evaluate a series of hotel characteristics when making purchasing decisions, such as hotel location, cleanliness, breakfast, service quality, and hardware facilities, etc [23]. Extremely negative reviews express consumers' strong dissatisfaction and they will be perceived more helpful when they are longer and thus provide more aspects of hotel information or details to support for the extreme evaluation compared to shorter ones, making the extremely negative review more credible. Therefore, we hypothesize the following:

H4. Review length can moderate the influence that extremely negative reviews have on review helpfulness. Compared with shorter negative reviews, the positive influence of extremely negative reviews on review helpfulness of longer negative reviews is stronger.

\section{METHODOLOGY \\ Data Collection}

This study focused on online reviews of accommodation. We choose online customer reviews posted on Ctrip.com as our data for various reasons: (1) Ctrip.com is the largest comprehensive travel service website including hotel reservation, ticket booking, holiday products and tourism information query service in China. It owns a large number of users to provide enough sample data for this study. (2) The data from Ctrip.com is usually used in previous studies, indicating that the data of this website had high credibility to some extent. Meanwhile, to reduce the regional difference, we limited our data collection to a single country. We decided to focus on Beijing hotels because the booming hotel industry in this country covers all types of hotels and thus can provide sufficient data and abundant information for this study.

Since Ctrip.com presents negative reviews separately alone in the review system, it is not only convenient for consumers to search for information, but also convenient for data collection during this study. We used data crawling software to retrieve 96007 negative reviews. For each review, the following information was collected: review score, review text, photo number and helpfulness votes received; In terms of hotel information, the hotel star level, the total number of hotel reviews and the average rating of the hotel were collected; In terms of reviewer information, reviewer rating, total reviews published and total helpfulness votes received were collected. Then, we screened out the sample of missing review text, repeated review and missing reviewer information. At the same time, in the process of data exploration, we found that the review score of some reviews is greater than or equal to 3 points, but the content of these reviews is not negative. Based on the definition of negative reviews in this paper and the reality, we chose to delete these sample and 86930 effective reviews remained as the research data.

\section{Research Variables}

Our research model includes 10 variables, as shown in Table-1. The dependent variable in our model is "review helpfulness" and is measured using the number of helpful votes received by an online consumer review. The independent variable "review extremity" is a dummy variable and equals to 1 if the review score is 1, 0 otherwise. The moderate variables are "hotel star level" and "review photo" and "review length". The first is the value of hotel star level corresponds to different hotel rating, such as 2 for two-star hotels and below, 3 for three-star hotels, etc. The second is a dummy variable equal to 1 in case the review contains photo, 0 otherwise. The last is measured by the number of words in the review text. Previous studies have shown that the total number of reviews, the average score of reviews, the rank of reviewers, the total number of reviews posted by reviewers and the total number of helpful votes obtained by reviewers are all important factors affecting review helpfulness, so this paper incorporated them into the model as control variables. 
Table-1: Variable operationalization

\begin{tabular}{|c|c|c|c|}
\hline Variable type & Variable name & Operationalization & Reference \\
\hline $\begin{array}{l}\text { Dependent } \\
\text { variable }\end{array}$ & Review helpfulness & $\begin{array}{l}\text { The number of helpful votes received by an online } \\
\text { review }\end{array}$ & $\begin{array}{l}\text { Mudambi \& } \\
\text { Schuff, } 2010[5]\end{array}$ \\
\hline $\begin{array}{l}\text { Independent } \\
\text { variable }\end{array}$ & Review extremity & $\begin{array}{l}\text { A dummy equal to } 1 \text { if the review score is } 1,0 \\
\text { otherwise }\end{array}$ & $\begin{array}{l}\text { Filieri et al., } 2019 \\
{[14]}\end{array}$ \\
\hline \multirow[t]{3}{*}{$\begin{array}{l}\text { Moderator } \\
\text { variables }\end{array}$} & Hotel star & $\begin{array}{l}\text { The number of stars of a hotel, from } 2 \text { (two-star and } \\
\text { below) to } 5 \text { (five-star) }\end{array}$ & $\begin{array}{l}\text { Filieri et al., } 2018 \\
{[2]}\end{array}$ \\
\hline & Review photo & $\begin{array}{l}\text { A dummy variable equal to } 1 \text { in case the review owns } \\
\text { photos, } 0 \text { otherwise. }\end{array}$ & $\begin{array}{l}\text { Nazlan et al., } 2018 \\
\text { [45] }\end{array}$ \\
\hline & Review length & The number of words of an online review & $\begin{array}{l}\text { Mudambi \& } \\
\text { Schuff, } 2010[5]\end{array}$ \\
\hline \multirow[t]{5}{*}{$\begin{array}{l}\text { Control } \\
\text { variables }\end{array}$} & $\begin{array}{l}\text { Total number of } \\
\text { reviews }\end{array}$ & The number of reviews posted on the hotel & Filieri, 2015 [20] \\
\hline & $\begin{array}{l}\text { Average score of } \\
\text { reviews }\end{array}$ & The average rating of reviews of the hotel & Filieri, 2015 [20] \\
\hline & Reviewer rank & $\begin{array}{l}\text { Level of the contributor from } 1 \text { (New Reviewer) to } 3 \\
\text { (Talent Reviewer) }\end{array}$ & $\begin{array}{l}\text { Filieri et al., } 2018 \\
\text { [2] }\end{array}$ \\
\hline & $\begin{array}{l}\text { Number of reviews } \\
\text { posted }\end{array}$ & $\begin{array}{l}\text { The number of reviews posted on Ctrip.com by the } \\
\text { reviewer. }\end{array}$ & Yin, 2012 [16] \\
\hline & $\begin{array}{l}\text { Helpful votes obtained } \\
\text { by the reviewer }\end{array}$ & $\begin{array}{l}\text { The number of reviews posted on Ctrip.com by the } \\
\text { reviewer assessed as helpful by the others. }\end{array}$ & $\begin{array}{l}\text { Huang et al., } 2015 \\
\text { [22] }\end{array}$ \\
\hline
\end{tabular}

\section{Data Analysis}

This paper used negative binomial regression model to analyze sample data. This decision was taken for two reasons. First, as can be seen from Table-2, the distribution of the data about useful votes (dependent variable) appears to be skewed to the left side with most reviews did not receive any usefulness votes, and even after excluding them, the data still did not show a normal distribution, so the linear regression model is not applicable to this study. Second, since the number of usefulness votes is a counting variable, the most classical poisson regression model is considered first. However, poisson regression requires that the mean value of the data is equal to the variance, but in this study, the mean value of review helpfulness is 0.50 and the variance is 3.65 , indicating the existence of excessive dispersion of the data. In conclusion, negative binomial regression model is adopted in this paper.

Table-2: Distribution of review helpfulness votes.

\begin{tabular}{|l|l|l|}
\hline Votes value & Frequency & Proportion \\
\hline 0 & 66462 & $76.45 \%$ \\
\hline 1 & 12212 & $14.05 \%$ \\
\hline 2 & 4050 & $4.66 \%$ \\
\hline 3 & 1696 & $1.95 \%$ \\
\hline 4 & 854 & $0.98 \%$ \\
\hline 5 & 477 & $0.55 \%$ \\
\hline 6 & 310 & $0.36 \%$ \\
\hline 7 & 206 & $0.24 \%$ \\
\hline 8 & 156 & $0.18 \%$ \\
\hline 9 & 104 & $0.12 \%$ \\
\hline 10 & 75 & $0.09 \%$ \\
\hline $11-20$ & 242 & $0.28 \%$ \\
\hline $21-30$ & 47 & $0.05 \%$ \\
\hline$>30$ & 39 & $0.04 \%$ \\
\hline Total & 86930 & $100 \%$ \\
\hline
\end{tabular}

\section{RESULTS}

Table-3 shows the descriptive statistics of the sample. Specifically, the average number of reviews that are voted as helpful is 0.5 , with an average review length of 79.7 words per review. The average star of hotels is 3.12 , and $27 \%$ of reviews are extremely negative, $8 \%$ of the reviews contain photos. 
Table-3: Descriptive statistics

\begin{tabular}{|l|l|l|l|l|}
\hline Variable & Minimum & Maximum & Mean & Standard deviation \\
\hline Dependent variable & & & & \\
\hline Review helpfulness & 0 & 219 & 0.50 & 1.91 \\
\hline Independent variable & & & & \\
\hline Review extremity & 0 & 1 & 0.27 & 0.44 \\
\hline Moderator variables & & & & \\
\hline Hotel star & 2 & 5 & 3.12 & 1.11 \\
\hline Review photo & 0 & 1 & 0.08 & 0.27 \\
\hline Review length & 1 & 3929 & 53.49 & 80.73 \\
\hline Control variable & & & & \\
\hline Total number of reviews & 9 & 13771 & 3008.50 & 2645.94 \\
\hline Average score of reviews & 2.9 & 4.9 & 4.27 & 0.34 \\
\hline Contributor level & 1 & 3 & 1.64 & 0.67 \\
\hline Number of reviews posted & 1 & 1837 & 13.34 & 26.98 \\
\hline Helpful votes obtained by the reviewer & 0 & 1650 & 3.12 & 15.04 \\
\hline
\end{tabular}

In order to avoid the problem of multicollinearity among variables, we tested for multicollinearity. The result shows that all VIF values of variables are less than 4 and therefore the multicollinearity did not appear to be a problematic issue. Then, we use Stata software to conduct negative binomial regression analysis, and the analysis results were shown in Table-4. As can be seen from the table, the test result of Likelihood-ratio test of alpha $=0$ indicates that poisson regression's null hypothesis is rejected and negative binomial regression should be considered, which supports the model selection in this paper.

Hypothesis 1 investigated whether a more extremely negative review will receive more helpfulness votes. This hypothesis is supported because this effect is positive and significant $(b=0.14, p<$ 0.01 ). The positive coefficient of review extremity indicates that the more extreme the score of a negative review is, the more helpful the review is.
Hypothesis 2, which states that hotel star level can alleviate the positive influence of extremely negative reviews on review helpfulness, was supported $(b=0.17, p<0.01)$. Hence, compared with low-star hotels, the extremity of negative reviews of high-star hotels have a smaller positive impact on the review helpfulness.

Hypothesis 3 speculated that review picture could reinforce the positive influence of negative review extremity on review helpfulness. The results of moderation test showed a significant interaction effect $(\mathrm{b}=1.01, \mathrm{p}<0.01)$. That is, an extremely negative review is more likely to be voted as helpful if it contains photos.

Hypothesis 4, which investigated that review length could strengthen the positive effect of negative review extremity on review helpfulness, is supported (b $=0.0008, \mathrm{p}<0.01)$. In other words, extremely negative review is perceived as more helpful when the review is long.

Table-4: Negative binomial regression models. Dependent variable: Review helpfulness

\begin{tabular}{|l|l|l|}
\hline & M1 & M2 \\
\hline Variable & Coeff. (Std. err.) & Coeff. (Std. err.) \\
\hline Total number of reviews of hotel & $1.75 \mathrm{e}-07(3.21 \mathrm{e}-06)$ & $-0.00004(3.14 \mathrm{e}-06)^{* * * *}$ \\
\hline Average score of reviews & $0.80898(0.0252)^{* * * *}$ & $0.82855(0.02610)^{* * * *}$ \\
\hline Contributor level & $-0.17261(0.01740)^{* * *}$ & $-0.11656(0.01504)^{* * *}$ \\
\hline Number of reviews posted & $-0.01346(0.00059)^{* * *}$ & $-0.00512(0.00044)^{* * * *}$ \\
\hline Helpful votes obtained by the reviewer & $0.1169169(0.00203)^{* * *}$ & $0.03284(0.00122)^{* * * *}$ \\
\hline Review extremity & $0.14431(0.01845)^{* * *}$ & $0.17078(0.01772)^{* * * *}$ \\
\hline Hotel star & & $0.16857(0.00802)^{* * *}$ \\
\hline Review photo & & $1.01422(0.02327)^{* * * *}$ \\
\hline Review length & & $0.00778(0.00011)^{* * * *}$ \\
\hline Hotel star $\times$ Review extremity & & $-0.03876(0.01477)^{* * * *}$ \\
\hline Review photo $\times$ Review extremity & & $0.19054(.05099)^{* * * *}$ \\
\hline Review length $\times$ Review extremity & & $0.00082(0.00024)^{* * *}$ \\
\hline Alpha & $3.27364(0.03900)$ & $1.90466(0.02750)$ \\
\hline Likelihood-ratio test of alpha $=0$ & $6.1 \mathrm{e}+04^{* * *}$ & $3.9 \mathrm{e}+04^{* * * *}$ \\
\hline Log Likelihood & -71884.08 & -66994.75 \\
\hline LR Chi2 & 9007.63 & $18786.29^{* * * *}$ \\
\hline Pseudo R2 & 0.0590 & 0.1230 \\
\hline
\end{tabular}

Note: $\mathrm{N}=86930$; The non-standardized coefficients are reported; $* * * \mathrm{p}<0.01,{ }^{* * \mathrm{p}}<0.05,{ }^{*} \mathrm{p}<0.1$. 


\section{DISCUSSION}

By collecting and analyzing the hotel review data from Ctrip, this paper explores the relationship between the extremely negative reviews and review helpfulness and its boundary conditions. The main conclusions are as follows.

Extremely negative reviews (scored 1) are likely to be voted as more helpful by consumers. Because extremely negative ratings clearly express the reviewer's strong dissatisfaction with the quality of the product or service and is diagnostic for consumers to judge the quality of the product or service, which makes these reviews very helpful in consumption decision making. Our findings are consistent with the previous studies of Park et al., [10], Filieri et al., [2], Jiang [11] and Yan et al., [12].

Hotel star level has a significant moderating effect on the relationship between the extremely negative review and review helpfulness. When the hotel star level is higher, the positive effect of extremely negative review on review helpfulness is weaker. This conclusion accords with the confirmation bias theory. Hotel star level is a sign of the hotel product and service quality, so when the hotel star level is higher, the deviation of the low quality (received information) represented by the extremely negative review from the quality (previous belief) represented by the hotel's star level is greater, which violates consumers' previous belief, thereby reducing the influence and usefulness of extremely negative reviews.

We found that review photo moderates the impact of extremely negative review. As for negative reviews with photos (vs. without photos), review extremity has a stronger positive effect on review helpfulness. Compared with single text reviews, text reviews with photos can provide consumers with more forms of information clues to make inferences about the quality of a hotel's products or services before consuming it. Therefore, when extremely negative reviews are accompanied by photos, they will make the extremely negative reviews more credible and usefulness.

Review length was another moderator considered in this study. Our findings show that an extremely negative review is more likely to be voted as helpful if it is lengthy. This result can be explained by the fact that longer reviews tend to provide more sufficient evidence to substantiate their extreme evaluation, making these extremely negative reviews more credible and persuasive.

\section{Theoretical and Managerial Implications}

This paper has a number of theoretical contributions. First, Most previous studies have used positive and negative reviews as a whole to explore the impact of review extremity on review helpfulness, leading to some differences in research conclusions. This article takes negative reviews alone as the research object and finds that extremely negative reviews are more useful, further confirming the applicability of information diagnostic theory in the context of online reviews and broadening the scope of the theory's interpretation. At the same time, our findings differ from previous studies who studied all reviews as a whole and found that extreme reviews are perceived as less useful [13]. As a result, researchers should understand the difference between positive reviews and negative reviews and consider whether it is need to study them respectively in future research. Second, scholars have explored the direct impact of review extremity on review helpfulness, but lack of discussion of moderators. This paper proposes three moderating variables: hotel star level, review photo, and review length. We found that all three of them can significantly reduce or enhance the positive effect of extremely negative review, which adds to the empirical research on online review helpfulness. In addition, the moderating factor of hotel star level was first proposed by this article, which broadens the research field of review helpfulness and the applicable context of the confirmation bias theory.

Our findings also have interesting implications for retailers and review platforms that aim to offer helpful content. First, although previous research has shown that negative reviews are more helpful than positive ones, not all negative reviews have the same effect on consumers. The findings of this article help online platforms screen out more useful negative reviews to present to consumers, thereby reducing cognitive costs. Second, the research conclusion of this article helps online platforms guide reviewers to post more useful online reviews. For example, the platform can prompt consumers to increase the word number of reviews and add pictures to improve the usefulness of reviews when reviews write extremely negative reviews. Third, because negative reviews can reduce consumers' willingness to buy and thus reduce product or service sales, retailers and review platforms can quickly identify negative reviews that have a greater impact on consumers based on the research conclusions of this article (scored as 1 point, with photos, longer length), so as to respond and remedy according to the content of the reviews to reduce the negative impact of them. Finally, hotel star level, as a quality signal of hotel products and services, can effectively weaken the influence of extremely negative reviews. For low-star hotels, it is not only vital to attach importance to extremely negative reviews, but also to establish other signals that can characterize the quality of products or services, such as distinctive brands. 


\section{Limitations and Future Research}

Our study has some limitations. First, this article only uses Ctrip's review data as the research object. Some studies have shown that the type of platform is also one of the factors influencing the online review helpfulness [30, 31]. Different platform contexts may provide different findings, so future research may further consider expanding the type of platform and enriching data sources. Second, whether our research conclusions are applicable to other cities or other product types (such as search products) is unknown, so we suggest future researchers to compare reviews of hotels from different countries as well as reviews of other product types. In addition, the study only considers three moderating variables: hotel star level, review photo, and review length. Future studies can consider other moderating variables from the characteristics of reviewer and review reader.

\section{REFERENCES}

1. Hong $\mathrm{H}, \mathrm{Xu} \mathrm{D}$, Wang GA, Fan W. Understanding the determinants of online review helpfulness: A meta-analytic investigation. Decision Support Systems. 2017 Oct 1;102:1-11.

2. Filieri R, Raguseo E, Vitari C. When are extreme ratings more helpful? Empirical evidence on the moderating effects of review characteristics and product type. Computers in Human Behavior. 2018 Nov 1;88:134-142.

3. Chipkin H. Consumer trends 2012: review websites [EB/OL]. 2012. http://www.travelweekly.com/Travel-

News/Online-Travel/Consumer-Trends-2012-

Review-websites, 2018-5-12.

4. Collie M. Internet leads travel [EB/OL]. http://www.geton.com/blog/geton/internet-leadstravel, 2018-5-27.

5. Mudambi S M, Schuff D. What makes a helpful online review? A study of customer reviews on amazon. com. MIS Quarterly. 2010;34(1):185-200.

6. Du X, Ding J, Xie Z. Lei L. An empirical study on the impact of online reviews on consumers' purchasing intention. Management Review. 2016;28:173-183.

7. Ye Q, Law R, Gu B. The impact of online user reviews on hotel room sales. International Journal of Hospitality Management. 2009 Mar 1;28(1):180-182.

8. Liao J, Huang M. Online product reviews, brands and product sales: An empirical study based on sales of hotel. Chinese Journal of Management, 2016;13(1), 122-130.

9. Ullah R, Amblee N, Kim W, Lee H. From valence to emotions: Exploring the distribution of emotions in online product reviews. Decision Support Systems. 2016 Jan 1;81:41-53.

10. Park S, Nicolau JL. Asymmetric effects of online consumer reviews. Annals of Tourism Research. 2015 Jan 1;50:67-83.

11. Jiang $X$. What is the most helpful product review?
The effect of online reviews' quantitative and textual features on its helpfulness. Foreign Ecomomics \& Management, 2015;37(4):41-55.

12. Yan Q, Meng Y. Factors affecting the perceived usefulness of online reviews-An empirical study based on online film reviews. Chinese Journal of Management Science, 2013;21(S1):126-131.

13. Yin G, Liu W, Zhu S. What Makes a Helpful Online Review? - The Perspective of Information Adoption and Social Network. Library and Information Service. 2012;16:140-147.

14. Filieri R, Raguseo E, Vitari C. What moderates the influence of extremely negative ratings? The role of review and reviewer characteristics. International Journal of Hospitality Management. 2019 Jan 1;77:333-341.

15. Zhao Z, Cui X. The effect of review valence, new product types and regulatory focus on new product online review usefulness. Acta Psychologica Sinica. 2015 Apr 25;47(4):555-568.

16. Yin $\mathrm{G}$. What kind of online reviews do consumers find more useful?- The influence effect of social factors. Management World, 2012;(12):115-124.

17. Yang SB, Hlee S, Lee J, Koo C. An empirical examination of online restaurant reviews on Yelp. com: A dual coding theory perspective. International Journal of Contemporary Hospitality Management. 2017 Feb 13;29(2):817-839.

18. Liu W, Xu PT. A Study on Influencing Factors of the Helpfulness of Online Reviews in $\mathrm{O} 2 \mathrm{O}$ of Restaurant Industry--Based on Tobit Model. Chinese Journal of Management Science. 2014;5(24):168-176.

19. Yuanyuan H, Qiang Y, Yijun L. Research on online impact factors of customer reviews usefulness based on movie reviews data. Journal of Management Sciences in China. 2010;13(8):7888.

20. Filieri R. What makes online reviews helpful? A diagnosticity adoption framework to explain informational and normative influences in eWOM. Journal of Business Research, 2015;68(6):1261-1270.

21. Liu Z, Park S. What makes a useful online review? Implication for travel product websites. Tourism Management. 2015 Apr 1;47:140-151.

22. Huang AH, Chen K, Yen DC, Tran TP. A study of factors that contribute to online review helpfulness. Computers in Human Behavior. 2015 Jul 1;48:17-27.

23. Filieri R, Hofacker CF, Alguezaui S. What makes information in online consumer reviews diagnostic over time? The role of review relevancy, factuality, currency, source credibility and ranking score. Computers in Human Behavior. 2018 Mar 1;80:122-131.

24. Li J, Zhan L. Online persuasion: How the written word drives WOM [J]. Journal of Advertising Research, 2011;51(1):239-257.

25. Yin DZ, Mitra M, Zhang H. When do consumers 
value positive vs negative reviews? [J]. Information Systems Research, 2016;27(1):131144.

26. Mafael A, Gottschalk SA, Kreis H. Examining biased assimilation of brand-related online reviews. Journal of Interactive Marketing, 2016;36:91-106.

27. Zhang JQ, Craciun G, Shin D. When does electronic word-of-mouth matter? A study of consumer product reviews. Journal of Business Research, 2010;63(12), 1336-1341.

28. Park DH, Kim S. The effects of consumer knowledge on message processing of electronic word-of-mouth via online consumer reviews. Electronic Commerce Research and Applications, 2008;7(4), 399-410.

29. Shin SY, Van Der Heide B, Beyea D, Dai YN, Prchal B. Investigating moderating roles of goals, reviewer similarity, and self-disclosure on the effect of argument quality of online consumer reviews on attitude formation. Computers in Human Behavior. 2017 Nov 1;76:218-226.

30. Xiang Z, Du Q, Ma Y, Fan W. A comparative analysis of major online review platforms: Implications for social media analytics in hospitality and tourism. Tourism Management. 2017 Feb 1;58:51-65.

31. Li W, Wang Z. Impact of the e-WOM platforms on consumer product judgment: A perspective on attribution theory. Chinese Journal of Management. 2011;8:1345-1352.

32. Purnawirawan N, De Pelsmacker P, Dens N. Balance and sequence in online reviews: How perceived usefulness affects attitudes and intentions. Journal of interactive marketing. 2012 Nov 1;26(4):244-255.

33. Zhai Y, Zhang X, Dao R, Li J. Research on the usefulness of online reviews in catering trade. In2017 3rd International Conference on Information Management (ICIM) 2017 Apr 21 (pp. 247-251). IEEE.

34. Wang C, He S, Wang K. Research on how additional review affects perceived usefulness of review. Journal of Management Science, 2015;28(3):102-114.

35. Chen Z, Lurie NH. Temporal contiguity and negativity bias in the impact of online word of mouth. Journal of Marketing Research. 2013 Aug;50(4):463-476.

36. Baumeister RF, Bratslavsky E, Finkenauer C, Vohs KD. Bad is stronger than good. Review of general psychology. $2001 \mathrm{Dec} ; 5(4): 323-370$.

37. Feldman JM, Lynch JG. Self-generated validity and other effects of measurement on belief, attitude, intention, and behavior. Journal of applied Psychology. 1988 Aug;73(3):421-435.

38. Bone PF. Word-of-mouth effects on short-term and long-term product judgments. Journal of business research. 1995 Mar 1;32(3):213-223.

39. Nickerson RS. Confirmation bias: A ubiquitous phenomenon in many guises. Review of general psychology. 1998 Jun;2(2):175-220.

40. Ghasemaghaei M, Eslami SP, Deal K, Hassanein $\mathrm{K}$. Reviews' length and sentiment as correlates of online reviews' ratings. Internet Research. 2018 Jun 4;28(3):544-563.

41. Kim M, Lennon S. The effects of visual and verbal information on attitudes and purchase intentions in internet shopping. Psychology \& Marketing. 2008 Feb;25(2):146-178.

42. Mitchell AA, Olson JC. Are product attribute beliefs the only mediator of advertising effects on brand attitude?. Journal of marketing research. 1981 Aug;18(3):318-332.

43. Filieri R. What makes an online consumer review trustworthy?. Annals of Tourism Research. 2016 May 1;58:46-64.

44. Pan, Y, Zhang J Q. Born unequal: A study of the helpfulness of user-generated product reviews. Journal of Retailing. 2011; 87(4):598-612.

45. Nazlan NH, Tanford S, Montgomery R. The effect of availability heuristics in online consumer reviews. Journal of Consumer Behaviour. 2018 Sep;17(5):449-60. 